$12-1993$

\title{
Adsorption Equilibrium of Benzene-P-Xylene Vapor Mixture on Silicalite
}

Jianmin Li

Cleveland State University

Orhan Talu

Cleveland State University

Follow this and additional works at: https://engagedscholarship.csuohio.edu/encbe_facpub

Part of the Membrane Science Commons

How does access to this work benefit you? Let us know!

Publisher's Statement

NOTICE: this is the author's version of a work that was accepted for publication in Chemical Engineering Science. Changes resulting from the publishing process, such as peer review, editing, corrections, structural formatting, and other quality control mechanisms may not be reflected in this document. Changes may have been made to this work since it was submitted for publication. A definitive version was subsequently published in Chemical Engineering Science, 49, 2, (January 1994) DOI 10.1016/0009-2509(94)80037-5

\section{Original Citation}

$\mathrm{Li}$, J., , \& Orhan, T. (1994). Adsorption equilibrium of benzene-p-xylene vapor mixture on silicalite. Chemical Engineering Science, 49(2), 189-197. doi:10.1016/0009-2509(94)80037-5

\section{Repository Citation}

$\mathrm{Li}$, Jianmin and Talu, Orhan, "Adsorption Equilibrium of Benzene-P-Xylene Vapor Mixture on Silicalite" (1993). Chemical \& Biomedical Engineering Faculty Publications. 69.

https://engagedscholarship.csuohio.edu/encbe_facpub/69

This Article is brought to you for free and open access by the Chemical \& Biomedical Engineering Department at EngagedScholarship@CSU. It has been accepted for inclusion in Chemical \& Biomedical Engineering Faculty Publications by an authorized administrator of EngagedScholarship@CSU. For more information, please contact library.es@csuohio.edu. 


\title{
ADSORPTION EQUILIBRIUM OF BENZENE-p-XYLENE VAPOR MIXTURE ON SILICALITE
}

\author{
JIANMIN LI and ORHAN TALU ${ }^{\dagger}$ \\ Department of Chemical Engineering, Cleveland State University, Cleveland, OH 44115, U.S.A.
}

\begin{abstract}
Adsorption equilibrium of benzene-p-xylene vapor mixture on silicalite is measured at $70^{\circ} \mathrm{C}$ with a specially designed cyclic volumetric apparatus at pressure levels of 2.53 and $1.20 \mathrm{kPa}$. The isobaric isotherms are S-shaped, and selectivity curves at different pressures cross over; the $p$-xylene selectivity at $2.53 \mathrm{kPa}$ is higher than that at $1.20 \mathrm{kPa}$ over a certain composition range. The heterogeneous ideal adsorbed solution (HIAS) model implemented on two patches qualitatively predicts these highly unusual behavior. The observed extraordinary phenomena are attributed to structural heterogeneity, a result of the tight-fit of sorbate molecules in silicalite pores. The success of HIAS attests to the paramount importance of adequate representation of heterogeneity in adsorption models.
\end{abstract}

\section{INTRODUCTION}

The pore size of pentasil zeolites are comparable to molecular sizes of many commercially important aromatic and substituted paraffinic compounds enabling shape selectivity which is the basis of many important processes. ZSM type zeolites have been widely used as shape selective adsorbents and zeolitic catalysts, mostly in aromatic processing. It is commonly agreed (Chang, 1983; Wu et al., 1983; Talu et al., 1989) that the pentasil zeolitic structure is responsible for the unique adsorptive and catalytic properties of aromatic-ZSM system. Silicalite, which theoretically does not contain any aluminum, is the end member of the pentasil family and it is isostructural with ZSM zeolites. The physical effects in aromatic pentasil zeolite system such as shape selectivity caused by structural heterogeneity can be studied on silicalite without the complications introduced by the existence of cations in ZSM zeolites.

All past studies on adsorption of aromatic compounds in ZSM and silicalite have concentrated on pure component adsorption. Although there are some disagreements, following highly unusual pure component equilibrium behavior were commonly observed. (1) Isotherm shape changes from type-I to IV with decreasing temperature (Talu et al., 1989; Guo et al., 1989). (2) There are maxima and/or minima on the heat of adsorption curves measured by different techniques (Pope, 1986; Thamm, 1987a, b). (3) p-Xylene is heavily adsorbed by silicalite while $o$-xylene and $m$ xylene are almost completely excluded (Lohse and Fahlke, 1983; Wu et al., 1983). (4) Although one unit cell of silicalite can theoretically accommodate 12 and 8.8 molecules, respectively, of benzene and $p$-xylene, the experimental capacities are determined to be about 8 molecules/u.c. for both (Wu et al,, 1983; Thamm, 1987a, b; Guo et al., 1989; Talu et al., 1989).

In this paper, the binary equilibrium data of benzene/p-xylene vapor mixture on silicalite are reported

'Author to whom correspondence should be addressed. for the first time. Two isothermal $\left(70^{\circ} \mathrm{C}\right)$ isobaric equilibrium planes are investigated at 2.53 and $1.20 \mathrm{kPa}$. These data carry a wealth of information beyond what can be deduced from pure component data. As should be expected in lieu of pure component data, highly unusual behavior is also displayed by the binary system. The binary equilibria are qualitatively predicted by the HIAS model which is used to explain phenomenologically the unusual behavior.

\section{PURE COMPONENT EQUILIBRIA}

Type-IV isotherm is conventionally explained by monolayer-to-multilayer transition and capillary condensation in mesopores (Sing et al., 1985) which commonly results in hysteresis. For aromatic molecules in pentasil zeolites, multilayer formation is impossible since meso- or macropores do not exist. Furthermore, it is hard to envision a process at molecular scale which can result in adsorption hysteresis. Therefore, the classic models for type-IV behavior is not applicable to these systems.

Microscopic investigations such as NMR and XRD (Eckman and Vega, 1986; Mentzen and Bosselet, 1988; Reischman et al., 1988; etc.) identify two types of sorbate molecules with different mobility in pentasil-zeolite pore structure. Molecular calculations and simulations (Nowak et al., 1987; Grauert and Fiedler, 1988; Pickett et al., 1989; Schroder and Sauer, 1990; Schroder, 1991; Talu, 1991) have been already performed to elucidate microscopically the location of different mobility molecules in the structure. The molecular calculations identify three distinctly different locations in the pore system; straight channels (parallel to $b$-axis), zigzag channels (in the a-c plane), and their intersections. Unfortunately, statistically rigorous simulations which should unequivocally resolve the physical locations (patches) have not been performed yet partly due to very poor simulation statistics caused by the tight-fit of sorbate molecules in the pore structure ( $\mathrm{Li}$ and Talu, 1992). 
Several models/postulates have been proposed to interpret the anomalies of pure component aromatic adsorption in silicalite. Some of these are: (1) formation of dimers or large clusters (Beschmann et al., 1987; Thamm, 1987a, b; Thamm et al., 1988), (2) temperature-dependent re-arrangement of the adsorbate molecules (Stach et al., 1984), (3) cell-theory (Stach et al., 1988), (4) simplified Ising model with site exclusions (Lee et al., 1992), and (5) surface phase transition with structural heterogeneity (Talu et al., 1989; Guo et al., 1989). Among these models/postulates only the last one which stipulates two patches in the pores offers explicit mathematical formulations to handle isotherm data.

The "two-patch" concept proposed by Talu and his co-workers is a direct induction from observed typeIV behavior. Existence of the step in the isotherms was taken as the evidence for high cooperative lateral interactions which would normally result in a type-V (convex to pressure axis at origin) isotherm. The fact that measured isotherms are concave at origin was taken as the evidence for the existence of at least two patches. A multipatch model can also fit the macroscopic isotherm behavior but microscopic measurements by NMR and XRD justify the use of only two patches. The model expressed by the following equations was successful (Talu et al., 1989) in correlating benzene, toulene and $p$-xylene isotherms on silicalite over a wide range of temperature and pressure:

$$
\begin{gathered}
P=\frac{K^{J} n^{J} n^{\infty J}}{n^{\infty J}-n^{J}} \exp \left(\frac{n^{J}}{n^{\infty J}-n^{J}}-\frac{k}{T} \frac{n^{J}}{n^{\infty J}}\right) \\
(J=\text { patch index; } l \text { or } s) \\
n=n^{l}+n^{s} .
\end{gathered}
$$

In the model, type-I and type- $V$ behavior are displayed on individual patches by eq. (1), namely, spatch and $l$-patch. The overall system behavior is of type-IV, simply being the sum of the two individual patches, eq. (2). As temperature increases, the occupation on l-patch with type- $\mathrm{V}$ isotherm is reduced substantially. Above a certain temperature, the occupation on 1 -patch is negligible below saturation pressure; thus the overall isotherm becomes type-I.

To explain the dramatic shift in the occupation of only one patch at high temperatures, one needs to realize that adsorption equilibrium is controlled by the change in the Gibbs free energy $(\Delta G)$ rather than the change in enthalpy $(\Delta H)$. It has been shown that the entropic contribution plays a significant role for aromatic molecules in silicalite (Talu et al., 1991). Since aromatic molecules are highly restricted in the silicalite pores, the changes in entropy due to adsorption at different locations are substantially different. This is a crucial difference between the adsorbate behavior in tight-fit pores and that on flat (large pore) heterogeneous surfaces where entropy of adsorption is assured to be same for all patches. The occupational probability in tight pores is controlled by the delicate balance between $\Delta H$ and $T \Delta S$. As temperature in- creases, $T \Delta S$ contribution becomes more significant for the patch with more restriction on molecular mobility, and $T \Delta S$ overwhelms $\Delta H$ contribution above a certain temperature which translates to insiginificant adsorption on that patch. Molecular simulation results at infinite dilution (Li and Talu, 1993) also support the proposed patch filling mechanism.

\section{BINARY MODELS}

Molecular simulations are the preferred tools to examine fully the shape-selectivity at microscopic level. Unfortunately, rigorous molecular simulations cannot be performed for these systems by existing techniques within a reasonable computational time because of the tight-fit of the sorbate molecules in the pores (Li and Talu, 1992; Li, 1993). Therefore, we decided to predict macroscopically the binary behavior from pure component data and use the models to make deductions about the unusual binary behavior. Although such a macroscopic approach cannot provide information at molecular level, it nevertheless provides insight to some extent.

Binary data are not used in model calculations in order to provide a "clean" prediction which may be more suitable for phenomenological arguments. Binary predictions are carried out by two approaches both using the same two-patch pure component representation: (1) HIAS theory (Valenzuela et al., 1988) and (2) multicomponent van der Waals model (MvdW) (Hoory and Prausnitz, 1967; Van Ness, 1969).

HIAS (Valenzuela et al., 1988) is an extension of ideal adsorbed solution theory (IAST) (Myers and Prausnitz, 1965) to heterogeneous surfaces. The binary equilibrium relations with HIAS applied to two patches are

$$
\begin{aligned}
& P y_{1}=P_{1}^{o s}\left(\pi^{s}\right) x_{1}^{s}=P_{1}^{o l}\left(\pi^{l}\right) x_{1}^{l} \\
& P y_{2}=P_{2}^{o s}\left(\pi^{s}\right) x_{2}^{s}=P_{2}^{o l}\left(\pi^{l}\right) x_{2}^{l}
\end{aligned}
$$

where $P_{i}^{o s}$ and $P_{i}^{o l}$ are standard state pressures of component $i$ at the corresponding spreading pressures, $\pi^{s}$ on s-patch and $\pi^{l}$ on l-patch. The vapor is considered to be in equilibrium with two distinct adsorbate phases; therefore there are actually four equilibrium relations in eqs (3) and (4). The adsorbed amount on individual patches are calculated by

$$
\begin{aligned}
& \frac{1}{n^{s}}=\frac{x_{1}^{s}}{n_{1}^{o s}\left(\pi^{s}\right)}+\frac{x_{2}^{s}}{n_{2}^{o s}\left(\pi^{s}\right)} \\
& \frac{1}{n^{l}}=\frac{x_{1}^{l}}{n_{1}^{o l}\left(\pi^{l}\right)}+\frac{x_{2}^{l}}{n_{2}^{o l}\left(\pi^{l}\right)}
\end{aligned}
$$

where $n_{i}^{0}$ are the adsorbed amount of component $i$ at its standard state on each patch. The total "observed" amount adsorbed is the sum over the two patches:

$$
n_{t}=n^{l}+n^{s}
$$

Finally, the overall "observed" mole fractions are cal- 
culated by

$$
\begin{aligned}
& x_{1}=\frac{n^{s} x_{1}^{s}+n^{l} x_{1}^{l}}{n_{\mathrm{r}}} \\
& x_{2}=\frac{n^{s} x_{2}^{s}+n^{l} x_{2}^{l}}{n_{t}} .
\end{aligned}
$$

MvdW predictions are carried out by employing the following mixing rules for the van der Waals parameters (Hoory and Prausnitz, 1967; Van Ness, 1969):

$$
\begin{aligned}
\frac{1}{n_{i}^{\infty}} & =\frac{x_{1}}{n_{1}^{\infty}}+\frac{x_{2}}{n_{2}^{\infty}} \\
\alpha & =\alpha_{1} x_{1}^{2}+2 \alpha_{12} x_{1} x_{2}+\alpha_{2} x_{2}^{2} \\
\alpha_{12} & =\sqrt{\alpha_{1} \alpha_{2}} .
\end{aligned}
$$

The resulting equilibrium relations for a single patch $(\mathrm{Li}, 1993)$ are

$$
\begin{aligned}
& \ln \frac{K_{1} n_{1} n_{t}^{\infty}}{\left(n_{t}^{\infty}-n_{t}\right) P y_{1}}+\frac{n_{t} n_{t}^{\infty}}{n_{1}^{\infty}\left(n_{t}^{\infty}-n_{t}\right)}-\frac{k_{1}}{T} \frac{n_{1}}{n_{1}^{\infty}} \\
& -\sqrt{\frac{k_{1} k_{2}}{n_{1}^{\infty} n_{2}^{\infty}}} n_{2}=0 \\
& \ln \frac{K_{2} n_{2} n_{1}^{\infty}}{\left(n_{1}^{\infty}-n_{t}\right) P y_{1}}+\frac{n_{t} n_{1}^{\infty}}{n_{2}^{\infty}\left(n_{t}^{\infty}-m_{t}\right)}-\frac{k_{2}}{T} \frac{n_{2}}{n_{2}^{\infty}} \\
& -\sqrt{\frac{k_{1} k_{2}}{n_{1}^{\infty} n_{2}^{\infty}}} n_{1}=0 \text {. }
\end{aligned}
$$

Solution to the two sets of equations [eqs (13) and (14)] for the two patches under the same vapor conditions gives the partial amounts adsorbed on each patch. The observed surface phase properties are calculated similar to HIAS by eqs (7)-(9).

\section{EXPERIMENTAL}

Experiments of single component and binary mixtures were carried out at $70^{\circ} \mathrm{C}$ on a silicalite sample synthesized in our laboratories. The average crystal size was $50 \times 35 \times 35 \mu$ as determined by SEM analysis. X-ray diffraction showed better than $99 \%$ crystallinity and EDAX analysis did not show any measurable amount of aluminum in the sample. Silicalite samples were calcined at $550^{\circ} \mathrm{C}$ and activated at $350-400^{\circ} \mathrm{C}$ for at least $12 \mathrm{~h}$ under high vacuum before each run. Liquid benzene and $p$-xylene used in this study were of HPLC grade purchased from Aldrich Company.

Pure-component isotherms of benzene and $p$ xylene were gravimetrically measured with. a Cahn 1000 microbalance following common procedure. A special cyclic volumetric system shown in Fig. 1 was designed and built for the binary measurements. The volumes of different sections in the system were carefully measured with better than $0.5 \%$ accuracy. The temperatures of the two tanks, saturator and adsorption column, counting $98 \%$ of the total volume, were controlled by water baths. During experiments, the vapor phase was circulated by a metal bellows pump through the adsorption column and the saturator which contained known composition liquid mixture of benzene and $p$-xylene and served as a vapor-liquid equilibrium (VLE) cell. The vapor phase properties were controlled by the VLE in the saturator. Zero grade $(99.995 \%)$ helium gas was used to facilitate the circulation of vapor phase. A flow controller in circulation loop was utilized for different purposes, e.g. fast circulation during vapor mixing for $\mathrm{GC}$ analysis and slow circulation during equilibrium to limit pressure drop in the adsorption column.

Since VLE data are not available for this system at low pressure, vapor phase composition and total pres-

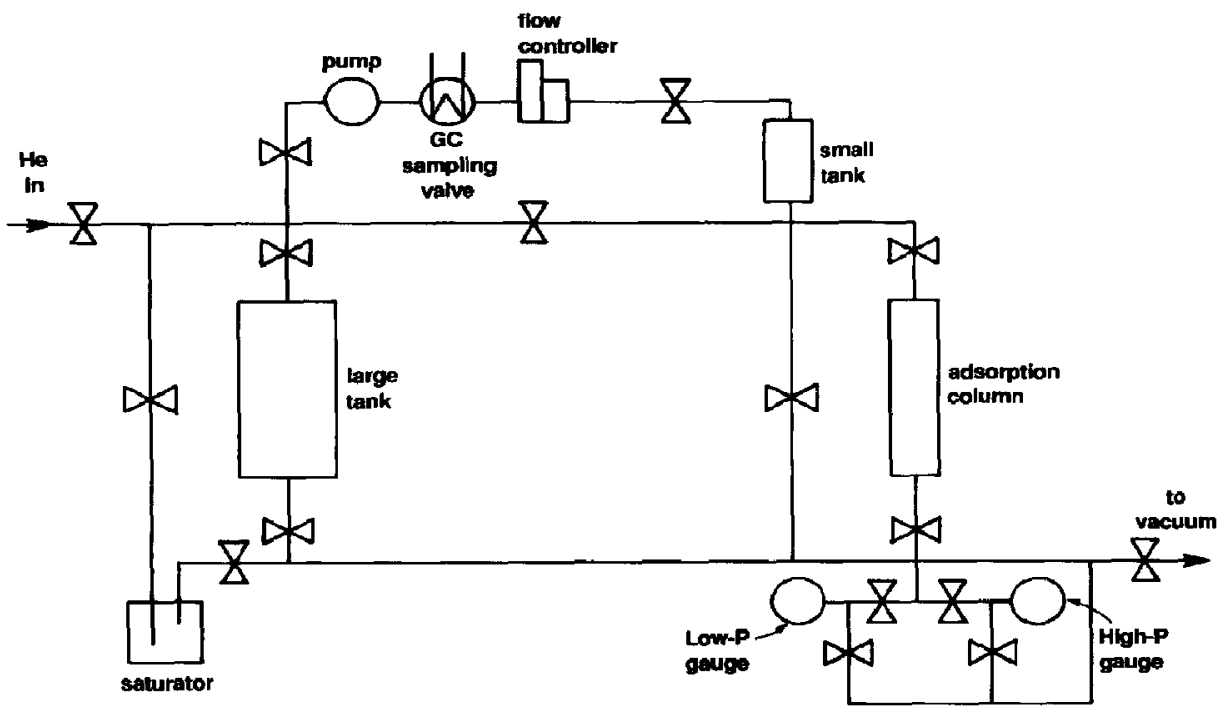

Fig. 1. Schematic of the cyclic volumetric apparatus for binary measurement. 
sure at equilibrium were determined by employing different $G C$ techniques. The total active pressure of aromatics was resolved by using a thermal conductivity detector (TCD) with hydrogen as the carrier gas. The mole fraction of individual aromatics was determined by a flame ionization detector (FID) with nitrogen as the carrier gas. The details of complicated GC analysis are given elsewhere $(\mathrm{Li}, 1993)$.

The time for binary equilibration was estimated from single-component static adsorption experiments. It took about $8 \mathrm{~h}$ for benzene and $68 \mathrm{~h}$ for $p$-xylene to reach equilibrium with the static volumetric technique. Hence, the binary system was equilibrated over $3 \mathrm{~d}$. After the equilibrium had been reached, the vapor phase properties were analyzed by GC sampling. Adsorbed aromatics were then desorbed by heating the adsorption column to $350-400^{\circ} \mathrm{C}$ while condensing them in the small tank cooled with liquid nitrogen. Adsorbed amount and the composition in the adsorbate phase were obtained by evaporating the desorbate to the temperature-controlled large and small tanks, and by $\mathrm{GC}$ analysis.

Conceptually, a binary isobaric isotherm covering the whole composition range can be constructed by varying the saturator temperature. Unfortunately, this change was much limited between the melting point of benzene $\left(5.5^{\circ} \mathrm{C}\right)$ and the ambient temperature $\left(21^{\circ} \mathrm{C}\right)$. Owing to these temperature limits, it was not possible to measure the entire binary isotherm at the pressures of interest. The VLE estimations indicate that measurable vapor phase mole fraction ranges from 0.70 to 0.96 at $2.53 \mathrm{kPa}$, and from 0.26 to 0.86 at $1.20 \mathrm{kPa}$, as shown in Fig. 2. It should be noted that the VLE calculations were made possible by extrapolating the Antoine equation for $p$-xylene below its melting point $13.2^{\circ} \mathrm{C}$.

Binary data were collected at pressure levels around 2.53 and $1.20 \mathrm{kPa}$ with about $10 \%$ fluctuation from point to point caused by the difficulties in presetting vapor phase properties in the complicated

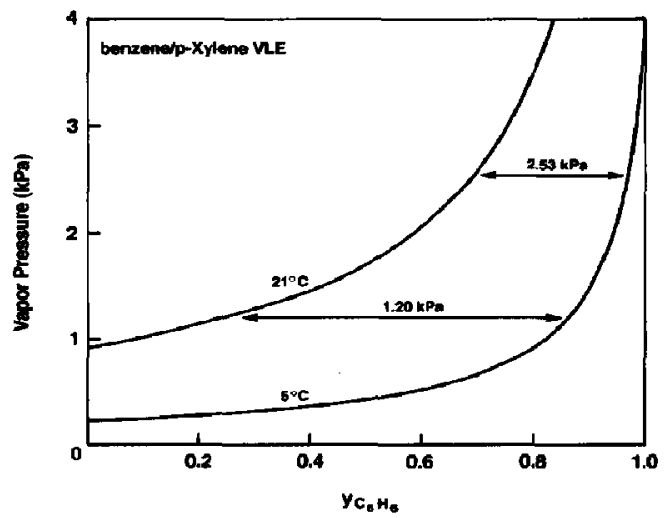

Fig. 2. Estimate of measurable composition ranges on isobaric planes by VLE calculations: (*) variation of saturator temperature is between benzene melting point and ambient temperature; (*) Antoine equation for $p$-xylene is extrapolated beyond its melting point. experimental procedure. This higher than desirable variation in pressure must be paid attention while examining the binary phase diagrams. Experimental errors were estimated to be $\pm 0.067 \mathrm{kPa}$ in pressure, $\pm 0.05^{\circ} \mathrm{C}$ in temperature, \pm 0.02 in mole fractions, and $\pm 0.02 \mathrm{mmol} / \mathrm{gm}$ in adsorbed amount.

\section{EXPERIMENTAL RESULTS}

Pure component data are tabulated in Table 1 and shown in Fig. 3. At $70^{\circ} \mathrm{C}$, benzene isotherm is essentially of type-I, and p-xylene isotherm is of type-IV with the first plateau at $c a 0.72 \mathrm{mmol} / \mathrm{g}$ which corresponds to about 4 molecules/u.c. occupancy. The two-patch vdW model was applied to the data presented here, and the parameter values are listed in Table 2. Correlations for both benzene and $p$-xylene are quite satisfactory as shown in Fig. 2. A single patch is enough to represent type-I benzene isotherm at $70^{\circ} \mathrm{C}$. Several studies have shown that at high temperatures adsorption of benzene is limited at $c a$ 4 molecules/u.c., half of the capacity at lower temperatures (Wu et al., 1983; Guo et al., 1989; Talu et al.,

Table 1. Experimental data of pure benzene and $p$-xylene on silicalite at $70^{\circ} \mathrm{C}$

\begin{tabular}{|c|c|c|}
\hline $\begin{array}{c}P^{\dagger} \\
(\mathrm{kPa})\end{array}$ & $\begin{array}{c}n \\
(\mathrm{mmol} / \mathrm{g})\end{array}$ & Method $^{\ddagger}$ \\
\hline \multicolumn{3}{|l|}{ Benzene } \\
\hline 0.005 & 0.425 & 1 \\
\hline 0.24 & 0.693 & 1 \\
\hline 0.37 & 0.698 & 1 \\
\hline 0.48 & 0.742 & 1 \\
\hline 0.69 & 0.747 & 1 \\
\hline 1.00 & 0.773 & 1 \\
\hline 1.19 & 0.774 & 2 \\
\hline 1.52 & 0.794 & 2 \\
\hline 1.80 & 0.847 & 1 \\
\hline 2.48 & 0.833 & 2 \\
\hline 2.71 & 0.842 & 2 \\
\hline 3.39 & 0.888 & 1 \\
\hline 5.72 & 0.924 & 1 \\
\hline \multicolumn{3}{|l|}{ p-Xylene } \\
\hline 0.013 & 0.218 & 2 \\
\hline 0.040 & 0.437 & 2 \\
\hline 0.145 & 0.691 & 1 \\
\hline 0.160 & 0.697 & 2 \\
\hline 0.245 & 0.713 & 1 \\
\hline 0.253 & 0.713 & 2 \\
\hline 0.320 & 0.722 & 2 \\
\hline 0.325 & 0.724 & 1 \\
\hline 0.400 & 0.736 & 2 \\
\hline 0.435 & 0.739 & 1 \\
\hline 0.540 & 0.957 & 1 \\
\hline 0.635 & 0.973 & 1 \\
\hline 0655 & 1.001 & 1 \\
\hline 0.750 & 1.022 & 1 \\
\hline 0.853 & 1.050 & 3 \\
\hline 1.075 & 1.045 & 1 \\
\hline
\end{tabular}

${ }^{+}$Pressure gauges have either $0.1 \mathrm{mbar}$ or 0.1 torr precision of readings.

†: gravimetric measurement on Cahn 1000 microbalance, 2: volumetric measurement on the binary apparatus, 3 : cyclic measurement on the binary apparatus. 


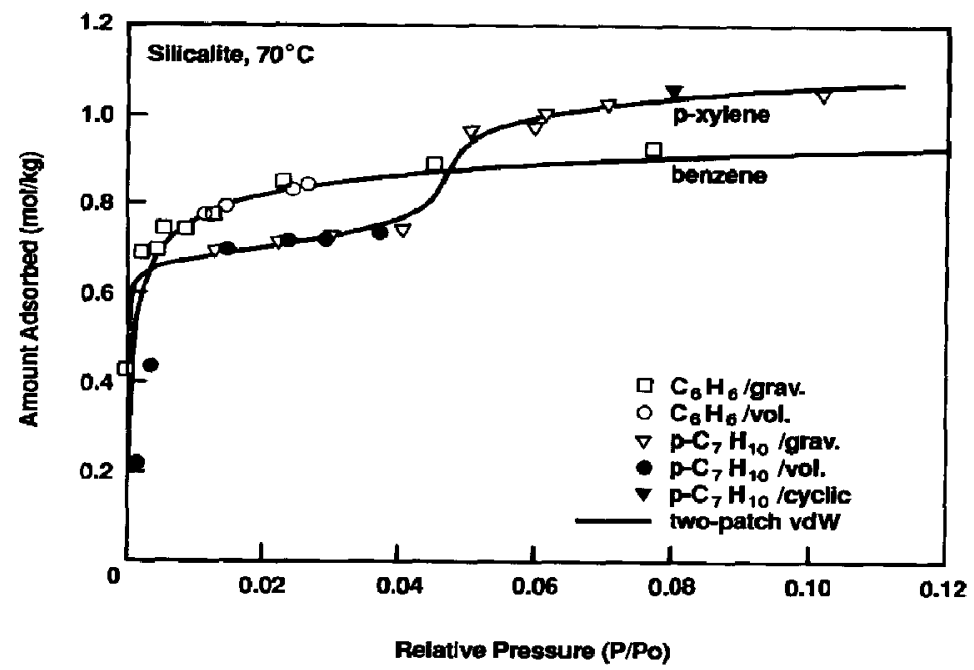

Fig. 3. Pure component isotherms of benzene and $p$-xylenc on silicalite at $70^{\circ} \mathrm{C}$ and their two-patch vdW correlations.

Table 2. Two-patch vdW model parameters

\begin{tabular}{lccccc}
\hline & $\begin{array}{c}K_{s} \\
{[\mathrm{kPa} /(\mathrm{mol} / \mathrm{kg})]}\end{array}$ & $\begin{array}{c}n_{s}^{\infty} \\
(\mathrm{mol} / \mathrm{kg})\end{array}$ & $\begin{array}{c}K_{l} \\
{[\mathrm{kPa} /(\mathrm{mol} / \mathrm{kg})]}\end{array}$ & $\begin{array}{c}n_{l}^{\infty} \\
(\mathrm{mol} / \mathrm{kg})\end{array}$ & $\begin{array}{c}k \\
(\mathrm{~K})\end{array}$ \\
\hline $\begin{array}{l}\text { Benzene } \\
p \text {-Xylenc }\end{array}$ & 0.061 & 1.179 & & & 0 \\
\hline
\end{tabular}

1989). Benzene molecules occupy only one patch at high temperature $\left(70^{\circ} \mathrm{C}\right)$ as also been proved by Laser-Raman spectroscopy (Forste et al, 1987) where only a single absorption peak was observed.

The reliability of the complicated binary experimental procedure was checked by measuring pure component isotherms by three techniques: (1) gravimetric on the Cahn balance, (2) static volumetric, and (3) cyclic volumetric on the binary apparatus. The latter, with pure liquid in the saturator, was performed exactly like the binary experiments. These data are within $2 \%$ consistency as shown in Fig. 3 which indicates the reliability of cyclic volumetric procedure.

To check the existence of composition hysteresis, some data points were measured by first saturating the adsorption column with pure $p$-xylene (the heavy component) followed by equilibration at desired vapor composition. Composition hysteresis was not observed within experimental error.

Binary adsorbed amount data are shown in Fig. 4 and listed in Table 3. Broken curves in Figs 4 and 6 are hand drawn to aid visualization of highly complicated behavior of the data. A step change in total adsorbed amount exists at intermediate mole fractions. Isotherms at the two pressures shift from concave to convex as benzene mole fraction increases. Such phenomenon has never been reported before. There is only one point at each pressure level in addition to the pure component ends on the diagram to support this observation. These two points are actually the limit of composition ranges that can be measured as explained in the preceding section. Nevertheless, we are confident on the existence of steps in binary isotherms especially since the changes in adsorbed amount are more than $30 \%$ (>0.15 $\mathrm{mmol} / \mathrm{gm}$ ) which is well beyond the experimental error.

The binary data shown in Fig. 4 confirm with pure component limits, as required by thermodynamic consistency (Talu and Myers, 1988). The integral consistency test which must hold regardless of surface characteristics (i.e. heterogeneity) is also performed based on the following equation:

$$
\int_{0}^{P} \frac{n_{1}}{P_{1}} \mathrm{~d} P_{1}+\int_{P}^{0} \frac{n_{2}}{P_{2}} \mathrm{~d} P_{2}=\Psi_{1}-\Psi_{2} \quad \text { (const } T \text { ) }
$$

where $\Psi=\pi A / R T$. Numerical values for the integrals from binary data and the right-hand side from pure component data are listed in Table 4. Although there is some difference at $2.53 \mathrm{kPa}$, the data satisfy thermodynamic consistency within experimental error.

$p$-Xylene is preferentially adsorbed as indicated in the phase diagram (Fig. 5). The $x-y$ curves do not clearly reveal the nature of the system due to the scale, whereas the selectivity diagram shown in Fig. 6 shows the unusual behavior of this system. The selectivity of 
Table 3. Binary equilibrium data of benzene-p-xylene vapor mixture on silicalite at $70^{\circ} \mathrm{C}$ and two-patch HIAS predictions ${ }^{\dagger}$

\begin{tabular}{|c|c|c|c|c|c|c|c|}
\hline \multirow{2}{*}{$\begin{array}{c}P^{\ddagger} \\
(\mathbf{k P a})\end{array}$} & \multirow[b]{2}{*}{$y_{1}$} & \multicolumn{2}{|c|}{ Experimental } & \multicolumn{2}{|c|}{ Predicted HIAS } & \multicolumn{2}{|c|}{ Predicted $\mathbf{M v d W}$} \\
\hline & & $x_{1}$ & $n$ & $x_{1}$ & $n$ & $x_{1}$ & $n$ \\
\hline 2.37 & 0.963 & 0.693 & 0.862 & 0.721 & 0.814 & 0.956 & 0.847 \\
\hline 2.51 & 0.920 & 0.541 & 0.856 & 0.545 & 0.806 & 0.237 & 0.733 \\
\hline 2.57 & 0.821 & 0.290 & 0.898 & 0.319 & 0.854 & 0.066 & 0.797 \\
\hline 2.45 & 0.708 & 0.126 & 1.042 & 0.168 & 1.058 & 0.028 & 1.019 \\
\hline 1.20 & 0.949 & 0.638 & 0.787 & 0.620 & 0.767 & 0.923 & 0.786 \\
\hline 1.21 & 0.790 & 0.239 & 0.827 & 0.271 & 0.757 & 0.049 & 0.716 \\
\hline 1.20 & 0.736 & 0.211 & 0.810 & 0.219 & 0.764 & 0.037 & 0.730 \\
\hline 1.24 & 0.708 & 0.195 & 0.846 & 0.197 & 0.774 & 0.032 & 0.743 \\
\hline 1.20 & 0.597 & 0.141 & 0.824 & 0.126 & 0.835 & 0.018 & 0.812 \\
\hline 1.27 & 0.538 & 0.083 & 0.947 & 0.088 & 0.994 & 0.012 & 0.975 \\
\hline 1.29 & 0.500 & 0.104 & 0.871 & 0.077 & 1.014 & 0.011 & 0,997 \\
\hline 1.25 & 0.481 & 0.093 & 0.866 & 0.071 & 1.014 & 0.010 & 0.998 \\
\hline 1.36 & 0.318 & 0.031 & 1.058 & 0.039 & 1.054 & 0.005 & 1.045 \\
\hline 0.63 & 0.115 & 0.017 & 0.885 & 0.011 & 0.956 & 0.001 & 0.954 \\
\hline 0.93 & 0.551 & 0.116 & 0.780 & 0.109 & 0.780 & 0.016 & 0.762 \\
\hline 2.11 & 0.675 & 0.153 & 0.975 & 0.148 & 1.045 & 0.023 & 1.011 \\
\hline
\end{tabular}

' $n$ : total adsorbed amount, in $\mathrm{mmol} / \mathrm{gm}$ (silicalite).

${ }^{t}$ Pressure gauge has 0.1 torr precision of reading.

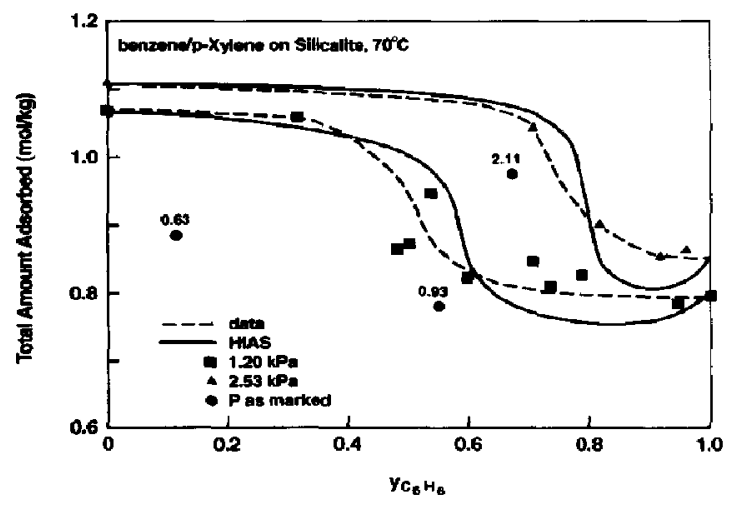

Fig. 4. Experimental adsorbed amount of benzene-p-xylene vapor mixture on silicalite at $70^{\circ} \mathrm{C}$ and predictions by HIAS (solid curves). Broken curves show experimental trends.

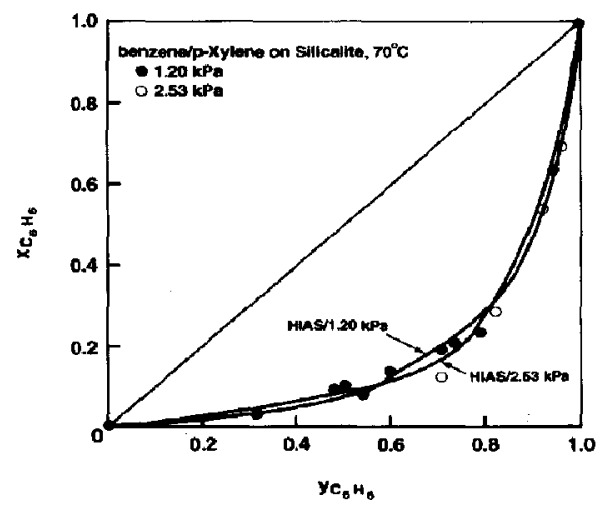

Fig. 5. Isothermal-isobaric phase diagram of benzene-pxylene vapor mixture on silicalite at $70^{\circ} \mathrm{C}$.
Table 4. Thermodynamic consistency test of binary data at $70^{\circ} \mathrm{C}$

\begin{tabular}{ccccc}
\hline $\begin{array}{c}P \\
(\mathrm{kPa})\end{array}$ & $\Delta \boldsymbol{\Psi}_{\text {binary }}$ & $\Delta \boldsymbol{\Psi}_{\text {pure }}$ & $\boldsymbol{\Psi}_{1}$ & $\boldsymbol{\Psi}_{2}$ \\
\hline 2.53 & -2.659 & -2.248 & 3.071 & 5.319 \\
1.20 & -2.095 & -2.052 & 2.455 & 4.507 \\
\hline
\end{tabular}

Note: $\Delta \Psi_{\text {binary }}=\int_{0}^{P} \frac{n_{1}}{P_{1}} \mathrm{~d} P_{1}+\int_{P}^{0} \frac{n_{2}}{P_{2}} \mathrm{~d} P_{2}$, by binary data. $\Delta \Psi_{\text {purc }}=\left(\frac{\pi A}{R T}\right)_{\text {pure 1 }}-\left(\frac{\pi A}{R T}\right)_{\text {pure 2 }}$, by pure component isotherms.

$\Psi_{1}, \Psi_{2}$ are evaluated from two-patch vdW model (Li, 1993).

p-xylene at high pressure is higher than that at low pressure in a certain composition range. Such behavior, to the best of our knowledge, has never been observed before. On the other hand, there is no rigorous thermodynamic argument to contradict this behavior, and we do not have any reason to suspect the data even though the conclusion is based on very few data points limited by the composition range shown in Fig. 2.

\section{DISCUSSION}

Both HIAS and MvdW are able to predict the abrupt change in adsorbed amount shown in Fig. 4 (MvdW predictions are not shown for the sake of clarity). The predicted location of step by both models is about the same which are higher than experimental locations. Despite the dislocation of the step and some disparity at high benzene compositions, both models predict the amount adsorbed reasonably well considering the very complex behavior of the system. One 


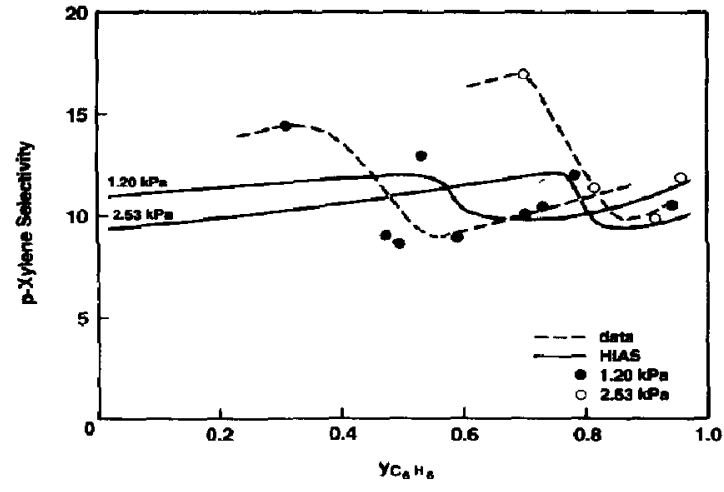

Fig. 6. Selectivities of $p$-xylene at $70^{\circ} \mathrm{C}$ and predictions by two-patch HIAS (solid curves). Broken curves show experimental trends.

should note the highly expanded scale in the figure for quantitative comparison.

The partial amounts adsorbed on each patch at $1.20 \mathrm{kPa}$ and $70^{\circ} \mathrm{C}$ calculated by HIAS are shown in Fig. 7. Examination of this figure indicates that the step change in the total adsorbed amount is related to the abrupt increase in p-xylene adsorption on the $l$-patch. This increase occurs at a partial pressure corresponding to the step on the pure p-xylene isotherm. Therefore, the total amount adsorbed abruptly increases at different compositions at two pressure levels as shown in Fig. 4. Normal competitive adsorption occurs on the $s$-patch where $p$-xylene is preferentially adsorbed.

HIAS predicts the phase diagram accurately as shown in Figs 4 and 5, while MvdW substantially overestimates $p$-xylene adsorbate mole fraction. As a result, the p-xylene selectivity predicted by MvdW are unrealistically high and are not included in Fig. 5. Although there is a difference between experimental and HIAS selectivities, the model qualitatively represents the data. HIAS predicts the double-crossovers of the selectivity at the two pressure levels. This unusual behavior is also linked to the abrupt change in $p$ xylene adsorbed amount on the l-patch. The abrupt change occurs at the same $p$-xylene partial pressure regardless of the total pressure, which in turn results in double crossover of selectivities at the two pressure levels.

An interesting finding is the ability of HIAS to predict the complex binary behavior even though it assumes ideal behavior in the surface phase. The model can be put through the stringent test with respect to partial amounts adsorbed. As shown in Fig. 7, HIAS predicts benzene behavior almost exactly, and it captures the essence of complicated $p$-xylene behavior. As evidenced by the steps on isotherms, the lateral interactions play a very important role in these systems which normally would make the ideal adsorbed phase assumption questionable. A mixture, on the other hand, can still behave ideal if the specific interaction between unlike molecules is

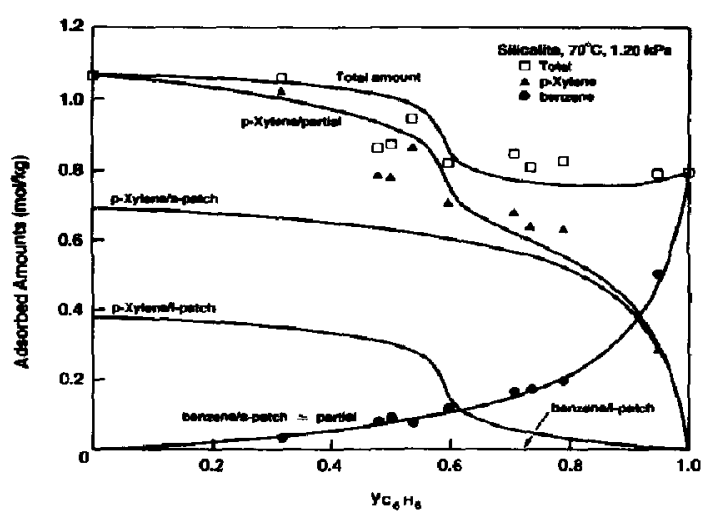

Fig. 7. Comparison of patch loadings for binary adsorption with two-patch HIAS at $70^{\circ} \mathrm{C}$ and $1.20 \mathrm{kPa}$. The l-patch is exclusive to benzene. Experimental partial amounts adsorbed are also shown to compare with model prediction.

close to that between like molecules regardless of the magnitude of lateral interactions. The lateral interactions in the binary are appropriately accounted by the HIAS through pure component information, thus the HIAS model can reasonably predict the equilibria. Previous applications of IAS and HIAS were successful at low surface coverage where lateral interactions were weak (Myers and Prausnitz, 1965; Myers, 1983; Valenzuela and Myers, 1984), resulting in a misconception that ideal surface phase behavior ignores adsorbate-adsorbate interactions (Myers, 1984). The system of interest here maybe the first reported one where the ideal assumption is applicable even though the lateral interactions play a major role.

The two-patch concept, originally a direct induction from type-IV isotherms, is crucial in explaining the behavior of aromatic molecules in silicalite. A major part of the successful prediction by HIAS should be attributed to this concept which correctly represents the structural heterogeneity. The HIAS treatment is essentially the conventional integral method commonly used for heterogeneous adsorption. The main disadvantage in applying the integral equation is the inevitable arbitrariness in choosing the local isotherm and the energy distribution simultaneously (Ross and Olivier, 1964). The system studied here is unique in that these choices can be made with confidence; XRD and NMR techniques and molecular simulations provide information about the "energy distribution" and the convex nature of type-IV isotherm provides information about the "local isotherm". These pieces of information are utilized in the pure component twopatch vdW model which is then accurately extended to binary predictions by the HIAS. This success should not be overlooked as an explanation for a specific system. It clearly demonstrates that heterogeneity is the major contribution to the "observed" non-ideality, as repeatedly stated before (Myers, 1983; O'Brien and Myers, 1987; Karavias and Myers, 1990).

One question still remains with the assumption of independent patches implicit in the integral equation 
and in HIAS. The topology of an adsorbent is commonly overlooked in heterogeneity models partly because of the ambiguity already introduced in choosing local isotherms and/or energy distributions. The "patches" in this system are about molecular size and they are regularly arranged in space. The interaction between molecules on different patches which is neglected in the model must be significant. These neglected "interpatch" interactions apparently do not have a bearing on the overall behavior as evidenced by the satisfactory HIAS prediction. This apparent contradiction does not exist if interpatch interactions are comparable to intrapatch interactions which are included in HIAS.

\section{CONCLUSION}

The sole effect of structural heterogeneity on binary adsorption is experimentally singled out for aromatic molecules adsorbed in silicalite. Two highly unusual phenomena are observed for the binary adsorption of benzene and $p$-xylene mixtures on silicalite: (1) the isobaric isotherm curves are $S$-shaped with a step change in adsorbed amount at intermediate composition, and (2) selectivity vs composition curves at different pressures cross over. These observations are attributed to "structural heterogeneity" which is significant for the system of interest because of the tight-fit of molecules in the silicalite pores. A seemingly very non-ideal competitive adsorption system is reported here for the first time which is solely controlled by structural heterogeneity. Similar trends are expected to be displayed by other shape-selective systems.

The binary behavior is qualitatively predicted by HIAS model combined with the "two-patch" concept. HIAS is applicable even though lateral interactions are significant since the cross-interaction between different types of molecules is similar to single-component interactions. Major part of the succcess in predicting the complicated binary behavior with HIAS is attributed to the correct representation of structural heterogeneity by the pure component two-patch vdW model. IAST assuming a homogeneous surface has totally failed in binary predictions (Li, 1993), once again proving that heterogeneity is the most important factor in determining surface phase behavior.

Acknowledgements-This work is supported under the Academic Challenge Program sponsored by the State of Ohio. Silicalite sample was kindly provided by Prof. David T. Hayhurst.

\section{NOTATION}

$A \quad$ specific adsorption area, $\mathrm{m}^{2} / \mathrm{kg}$ sorbent

$G \quad$ Gibbs free energy

$H \quad$ enthalpy

$k$ combined van der Waals constant $(=2 \alpha /$ $R / \beta)$

$K \quad$ Henry's constant

$n$ adsorbed amount, mol/ $\mathrm{kg}$ (silicalite)

$P \quad$ pressure, $\mathbf{k P a}$

$R \quad$ universal gas constant

$\begin{array}{ll}S & \text { entropy } \\ T & \text { temperature, } K \\ x & \text { mole fraction in adsorbate phase } \\ y & \text { mole fraction in vapor phase }\end{array}$

\section{Greek letters}

$\alpha \quad$ van der Waals interaction parameter

$\beta \quad$ van der Waals size parameter

$\pi \quad$ spreading pressure

$\sigma \quad$ molar area of adsorbates

$\Psi$ reduced spreading pressure, $\pi A / R T$

\section{Superscripts \\ $J \quad$ patch index \\ $l \quad l$-patch \\ $s \quad s$-patch \\ $0 \quad$ standard state \\ a adsorption capacity}

\section{Subscripts \\ 1,2 component index \\ $t$ total}

\section{REFERENCES}

Beschmann, K., Kokotailo, G. T. and Riekert, L., 1987, Kinetics of sorption of aromatics in zeolite ZSM-5. Chem. Engng Process 22, 223.

Chang, C. D., 1983, Hydrocarbons from methanol. Catal. Rev. Sci. Engng 25(1), 1.

Eckman, R. R. and Vega, A. J., 1986, Deuterium solid-state NMR study of the dynamics of molecules sorbed by zeolites. J. phys. Chem. 90, 4679.

Forste, C., Germanus, A., Karger, J., Pfeifer, H., Caro, J., Pilz, W. and Zikanova, A., 1987, Molecular mobility of methane adsorbed on ZSM-5 containing co-adsorbed benzene, and the location of the benzene molecules. $J$. chem. Soc. Faraday Trans. 83, 2301.

Grauert, B. and Fiedler, K., 1988, Monte Carlo calculations: thermodynamic functions in zeolites. II. Adsorption of benzene on silicalite. Adsorp. Sci. Technol. 5, 191.

Guo, C.-J., Talu, O. and Hayhurst, D. T., 1989, Phase transition and structural heterogeneity: benzene adsorption on silicalite. A.I.Ch.E. J. 35, 573.

Hoory, S. E. and Prausnitz, J. M., 1967, Monolayer adsorption of gas mixtures on homogeneous and heterogeneous solids. Chem. Engng Sci, 22, 1025.

Karavias, F. and Myers, A. L., 1990, Simulation of single and binary gas adsorption in zeolite cavities. Presented at Symposium on Statistical Mechanics of Adsorption, AIChE Annual Meeting, Chicago, 14 November.

Lee, C.-K., Chiang, A. S. T. and Wu, F. Y., 1992, Lattice model for the adsorption of benzene in silicalite $I$. A.I.Ch.E. J. 38, 128.

Li, J., 1993, Dissertation. Cleveland State University, Cleveland, $\mathrm{OH}$.

$\mathrm{Li}, \mathrm{J}$. and Talu, O., 1992, Effect of structural heterogeneity on multicomponent adsorption: benzene and p-xylene mixtures on silicalite, in Proceedings of the 4th International Conference on Fundamentals of Adsorption, Kyoto, Japan.

Li, J. and Talu, O., 1993, Structural effect on molecular simulations of tight-pore systems. J. chem. Soc. Faraday Trans. 89(11), 1683.

Lohse, U. and Fahlke, B., 1983, Adsorption of hydrocarbons on silicalite and ZSM 5 Lohse and Fahlke. Chem. Tech. (Leipzig) 35, 350.

Mentzen, B. F. and Bosselet, F., .1988, Characterization of guest molecules adsorbed on zeolites of known structure, Part III-localization of the $p$-XYLI and $p$-XYLII spe- 
cies sorbed in a high coverage B. ZSM-5/p-xylene complex. Mat. Res. Bull. 23, 227.

Myers, A. L., 1983, Activity coefficients of mixtures adsorbed on heterogeneous surfaces. A.I.Ch.E. J. 29, 691.

Myers, A. L., 1984, Adsorption of pure gases and their mixtures on heterogeneous surfaces, in Fundamentals of Adsorption (Edited by A. L. Myers and G. Belfort), p. 365. United Engineering Trustees.

Myers, A. L. and Prausnitz, J. M., 1965, Thermodynamics of mixed-gas adsorption. A.I.Ch.E. J. 11, 121.

Nowak, A. K., Cheetham, A. K., Pickett, S. D. and Ramdas, S., 1987, A computer simulation of the adsorption and diffusion of benzene and toluene in the zeolites theta-1 and silicalite. Molecular Simulation 1, 67.

O'Brien, J. A. and Myers, A. L., 1987, Activity coefficients for adsorption of laterally interacting molecules on a random heterogeneous solid surface, in Fundamentals of Adsorption (Edited by A. I. Liapis). United Engineering Trustees.

Pickett, S. D., Nowak, A. K., Thomas, J. M. and Cheetham, A. K., 1989, Computer simulation of the adsorption and diffusion of benzene in silicalite, theta-1, and a new zeolite, EU-1. Zeolites $9,123$.

Pope, C. G., 1986, Sorption of benzene, toluene, and pxylene on silicalite and H-ZSM-5. J. phys. Chem. 90, 835.

Reischman, P. T., Schmitt, K. D. and Olson, D. H., 1988, A theoretical and NMR study of p-xylene sorption into ZSM-5. J. phys. Chem. 92, 5165.

Ross, S. and Olivier, J. P., 1964, On Physical Adsorption. Wiley, New York.

Schroder, K.-P. and Sauer, J., 1990, Computer simulation of benzene in silicalite-1. Low-coveragè sorbate structures and diffusion barriers. $Z$. phys. Chem. Leipzig 271, 289.

Schroder, K.-P., 1991, Computer modelling of p-xylene sorption in ZSM-5/silicalite-1. Stud. Surf. Sci. Catal. 65, 435.

Sing, K. S. W., Everett, D. H., Haul, R. A. W., Moscou, L., Pierotti, R. A., Rouquerol, J. and Siemieniewska, T., 1985, Reporting physisorption data for gas/solid systems with special reference to the determination of surface area and porosity. Pure Appl. Chem. 57, 603.

Stach, H., Thamm, H., Janchen, J., Fiedler, K. and Schirmer, W., 1984, in Proceedings of the 6th International Confer- ence on Zeolites (Edited by A. Bisio, D. H. Olson). Butterworths, London.

Stach, H., Wendt, R., Fiedler, K., Grauert, B., Janchen, J. and Spindler, H., 1988, Cell-theoretical and molecular-statistical treatment of the pore filling of the pentasil-type zeolites by benzene molecules, in Characterization of Porous Solids (Edited by K. K. Unger et al.), p. 105. Elsevier, Amsterdam.

Talu, O., 1991, Behavior of aromatic molecules in silicalite by the direct integration of the configurational integral. Molecular Simulation 8, 119

Talu, O., Guo, C.-J. and Hayhurst, D. T., 1989, Heterogencous adsorption equilibria with comparable molecule and pore sizes. J. phys. Chem. 93, 7294.

Talu, O., Hayhurst, D. T. and Guo, C.-J., 1991, The effect of molecular structure on heterogeneity and surface phase transition, in: 3rd International Conference on Fundamentals of Adsorption, Sonthofen, Germany, 1989 (Edited by A. B. Mersmann and S. E. Scholl). United Engineering Trustees.

Talu, $O$. and Myers, A. L., 1988, Rigorous thermodynamic treatment of gas adsorption. A.I.Ch.E. J. 34, 1887.

Thamm, H., 1987a, Calorimetric study on the state of aromatic molecules sorbed on silicalite. J. phys. Chem. 91, 8 .

Thamm, H., $1987 \mathrm{~b}$, Adsorption site heterogeneity in silicalite: a calorimetric study. Zeolites 7,341 .

Thamm, H., Jerschkewitz, H.-G. and Stach, H., 1988, Calorimetric study on the state of benzene and cyclopentane sorbed on H-ZSM-5 with different $\mathrm{Si} / \mathrm{Al}$ ratios. Zeolites 8, 151.

Valenzuela, D. P. and Myers, A. L., 1984, Gas adsorption equilibria. Separ. Purif. Methods 13, 153.

Valenzuela, D. P., Myers, A. L., Talu, O. and Zwiebel, I., 1988, Adsorption of gas mixtures: effect of energetic heterogeneity. A.I.Ch.E. J. 34, 397.

Van Ness, H. C., 1969, Adsorption of gases on solids. Ind. Engng Chem. Fundam. 3, 464.

Wu, P., Debebe, A. and Ma, Y. H., 1983, Adsorption and diffusion of $C_{6}$ and $C_{8}$ hydrocarbons in silicalite. Zeolites 3, 118 